\title{
The development of ultrahigh and extreme high vacuum technology for physics research
}

\author{
H. F. Dylla ${ }^{\text {a) }}$ \\ Thomas Jefferson National Accelerator Laboratory, Newport News, Virginia 23606 \\ and Departments of Physics and Applied Science, College of William and Mary, \\ Williamsburg, Virginia 23185
}

\begin{abstract}
Over the last 50 years increasingly large and more sophisticated devices have been designed and put into operation for the study of particle and nuclear physics, magnetic confinement of high temperature plasmas for thermonuclear fusion research, and gravity wave observatories based on laser interferometers. The evolution of these devices has generated many developments in ultrahigh and extreme high vacuum technology that were required for these devices to meet their operational goals. The technologies that were developed included unique ultrahigh vacuum vessel structures, ultrahigh vacuum compatible materials, surface conditioning techniques, specialized vacuum pumps and vacuum diagnostics. Associated with these technological developments are scientific advancements in the understanding of outgassing limits of UHV-compatible materials and particle-induced desorption effects.

${ }^{a)}$ Electronic-mail: dylla@jlab.org
\end{abstract}




\section{INTRODUCTION}

The development of the science and technology of ultrahigh vacuum over the last 50 years has been strongly coupled to the development of increasingly larger and more sophisticated devices for physics research, such as particle accelerators, magnetic fusion devices and gravity wave observatories. This coupling has been bi-directional - sometimes innovations in vacuum technology have driven machine development, and sometimes the technology transfer has been reversed. In the last decade, several large physics research projects were initiated that are very dependent on frontier vacuum technology such as the Large Hadron Collider (LHC), currently under construction at CERN in Geneva, and the International Tokamak Engineering Reactor (ITER), which is continuing engineering design evolution at several international design centers, and several gravity wave observatories currently being commissioned across the globe. These are the current offspring in an evolution that began 80 years ago for particle accelerators, more than 50 years ago for magnetic fusion, and more than 30 years ago for gravity wave observatories.

During this evolution a wealth of ultrahigh vacuum technology has been developed for or incorporated into these machines, including unique vacuum vessel designs, vacuum sealing techniques, high performance vacuum materials, UHV and XHV cleaning and conditioning techniques, vacuum pumps, vacuum instrumentation and vacuum controls. This article highlights key scientific and technical advances driven by the necessity for appropriate vacuum environments for accelerating particle beams, for heating and confining high temperature plasmas, and more maintaining laser interferometers sufficiently noise free to detect the extremely weak vibrations of gravity waves. 


\section{PARTICLE ACCELERATORS AND STORAGE RINGS}

\section{A. The evolution of particle accelerators and the need for UHV}

A well-known diagram of the performance limits of various types of particle accelerators was first drawn by Stanley Livingston in his 1954 book High Energy Accelerators. [1] An extension of the original plot (Fig. 1) shows acceleration limits increasing by an order of magnitude every 6 years. The predicted trend remained surprisingly accurate through 1985 , largely because of the incorporation of new acceleration schemes roughly once a decade and the innovation of colliding beams versus fixed target experiments.

The family of accelerators that existed when Livingston first published his evolutionary diagram (i.e., electrostatic, cyclotrons, betatrons and synchrotrons) did not place significant demands on vacuum technology. As the machines grew larger their design gave engineers the opportunity to incorporate cost effective vacuum vessel fabrication techniques and vacuum pumping systems. The first incentive to incorporate UHV technology into accelerator designs came with the invention [2] of the storage ring based on a concept of Gerald K. O'Neill in 1956. O'Neill proposed a means of storing accelerated particles in a ring of strongly focused guiding magnets. Particles would be accelerated in a conventional synchrotron or linac and then injected into the storage ring. The full momentum transfer advantage of colliding beams could be obtained by intersecting counter-rotating beams from two identical storage rings. The advantage of intersecting beams for achieving high center-of-mass energies was suggested by Kerst et al. [3] at about the same time as O'Neill's description of the storage ring.

In O'Neill's first paper [2] on the storage ring concept, he estimated that storage times would be a few seconds in the typical ( $\sim 10^{-7}$ torr $)$ high vacuum environment. A follow-up paper published two years later by O'Neill and Woods [4] noted that if "vacuum technology already developed in thermonuclear power research [5] were employed, storage times would be hours." 
O'Neill began a collaboration with physicists at Stanford to construct two $500 \mathrm{MeV}$ electron storage rings. The Stanford-Princeton storage ring completed in 1961, along with a contemporary machine - the $250 \mathrm{MeV}$ electron storage ring AdA, built at the Frascati laboratories in Italy [6] — were milestones in accelerator machine physics. These were the first in a long succession of storage rings and colliders to be built over the next three decades. At least two important and related lessons were learned from the operation of the StanfordPrinceton collider which would affect the subsequent development of these machines. UHV conditions, and hence useful electron storage times, could not be maintained in the stainless steel vacuum chamber because of contamination from the appendage oil diffusion pumps. Second, a new phenomenon was recognized: a large dynamic outgassing effect was observed in the presence of stored electron beam that was attributed by O'Neill [7] to a two-step, gas desorption process, whereby the incident synchrotron radiation generates photoelectrons responsible for the gas desorption. The effect has subsequently been well studied by numerous groups [8] because it is the dominant gas load to be dealt with in the design of electron or positron storage rings.

The next storage ring built at Stanford, SPEAR, the "Stanford Positron-Electron Asymmetric Ring", [9] and the first proton storage ring, the Intersecting Storage Rings (ISR) [10] built at CERN, are significant milestones in both particle physics and UHV development. In general, storage ring vacuum chambers, because of their lengths and narrow cross sections, are highly conductance-limited. Dynamic beam-induced vacuum problems could not be solved simply by increasing the number of appendage vacuum pumping systems. Innovations were necessary to meet both performance and realistic construction cost goals involving: (1) new vacuum vessel design and fabrication techniques, (2) vacuum vessel conditioning techniques, (3) distributed vacuum pumps, and (4) UHV compatible synchrotron-radiation absorbers. 
The required dynamic pressures $\left(<10^{-9}\right.$ torr $)$ are approximately the same for achieving stable high current $(\geq 0.1$ A) stored beams with reasonable storage times ( $\sim$ hrs.) for both proton and electron rings - even though the offending gas-phase and surface interactions are different in the two cases. For proton rings, low gas pressures are required to minimize scattering of the beam and to minimize an instability that was first observed in the ISR. With insufficient vacuum and insufficiently cleaned vessel surfaces, ionized residual gas species repelled by the beam impact the surface, releasing more gas by ion-induced desorption. At pressures greater than $10^{-9}$ torr, the effect can avalanche, leading to quenching of the beam current [11]. Careful measurements of ion-induced desorption coefficients by Mathewson and Achard [12] show desorption coefficients greater than unity for unconditioned metal surfaces. With various combinations of vessel bakeout and discharge cleaning, ion-induced desorption coefficients can be lowered by two to three orders of magnitude.

The ISR, operated from 1971-1984, was a groundbreaking machine for both particle physics and the science and technology of ultrahigh vacuum. Proton beams with currents up to $20 \mathrm{~A}$ at energies up to $28 \mathrm{GeV}$ were stored in a pair of $1 \mathrm{~km}$ diameter rings. The ISR incorporated the best UHV techniques known at the time and the device was well instrumented to characterize the vacuum environment $[13,14]$. The ISR vacuum group developed several vessel material conditioning techniques that were used on many subsequent machines at CERN and elsewhere in many other vacuum applications to optimize UHV performance. As a result of a study of the diffusivity of hydrogen in stainless steel [15], sheet stock used for vessel fabrication was baked in vacuum for 2 hours at $900^{\circ} \mathrm{C}$, lowering the hydrogen content by an order of magnitude. Significant efforts were devoted to developing and qualifying the effectiveness of chemical recipes for cleaning vacuum materials [16] and to developing discharge cleaning methods using argon and argon/oxygen mixtures [17]. These surface 
conditioning studies were extended to aluminum surfaces [18] in the 1980's as CERN focused on the design of the $27 \mathrm{~km}$ Large Electron Positron (LEP) collider which operated from 1989 to 2000 [19].

At about the time the ISR device was being commissioned, the SPEAR device [20] at Stanford became operational (1972). Many of the design innovations developed for this collider were incorporated in subsequent electron-positron colliders and storage rings. Dynamic pressure requirements of $10^{-9}$ torr are also necessary for electron or positron storage rings, but in this case the primary gas scattering mechanism is bremsstrahlung losses in electron-molecule collisions [21]. The beam lifetime determined by this scattering mechanism scales inversely with molecular mass, thus putting a penalty on the higher molecular weight components of the residual gas. As mentioned earlier, the source of dynamic gas load is the synchrotron-radiationinduced desorption. This phenomenon is now well understood in terms of gas desorption by photoelectrons generated by synchrotron radiation. Measurements to study the phenomenon were first done with electron sources to simulate the photoelectron emission, including the early measurements by the SPEAR vacuum design team. Later, actual measurements of photoinduced desorption coefficients were obtained using beam lines on storage ring light sources by the vacuum groups at CERN [8, 19], Brookhaven [21], and KEK [22]. Measured desorption coefficients start out in the range of $10^{-2}$ to $10^{-1}$ depending on whether the substrate is stainless steel, aluminum or copper, and generally decrease inversely with the photon dose to $10^{-5}$ or $10^{-6}$ after a beam exposure that is typically 1 to 10 ampere-hours, corresponding to a photon dose of $10^{22}$ to $10^{23}$ photons per meter of vacuum vessel. This "beam cleaning" effect has turned out to be the most efficient in-situ, surface-conditioning technique for electron storage rings. The synchrotron emission which generates the photo-emitted electrons, and the resulting photoemission rate, can be calculated for a given set of electron beam parameters and knowledge 
of the vacuum vessel geometry. Combining the results of these calculations with the measured photo-induced desorption coefficients allows the designers of new machines to design the vacuum chambers and associated pumping systems. Some effort has been made to model [23] the dose dependence of the photo-induced desorption which is clearly rate-limited by the diffusion of $\mathrm{H}, \mathrm{C}$, and $\mathrm{O}$ species from the near-surface of the bombarded metal.

\section{B. Storage ring vacuum vessel and pumping system developments}

The large dynamic gas loads that are present in electron storage rings have driven the development of unique vacuum chambers and associated pumping systems in order to meet the UHV operating requirements. Solutions adopted for the SPEAR storage ring [24] were innovative and became prototypical for the next three decades of storage ring design. The use of a simple pipe-like geometry for accelerator vacuum chambers with appendage pumping ports spaced at convenient intervals between magnet gaps is sufficient for the modest vacuum requirements of most circular accelerators. Typically, pumping speeds per unit length of chamber of the order of 1-10 $\lambda / \mathrm{s}-\mathrm{m}$ can be obtained with appendage pumping. To cope with the synchrotron- radiation-induced gas load in an electron storage ring, so-called distributed pumps were placed within the beam chambers based either on sputter ion pumps placed within the bending magnet field or non-evaporable getters (NEGs).

The innovative SPEAR vacuum chamber was fabricated using an aluminum (type 6061) extrusion technique.[24] This was a cost-effective solution for producing a long (200 m), multichambered, non-concentric vessel. A cooling channel and ridged surface were extruded in the outer face of the chamber to deal with the localized heat load from incident synchrotron radiation. Many storage rings built after SPEAR, particularly those specifically designed as synchrotron light sources, have taken advantage of extruded aluminum chambers, because of the 
ease of fabrication and the ability to deal with the synchrotron radiation heat loads with coextruded cooling channels (and the intrinsic high thermal conductivity of aluminum). Extruded chamber designs made after SPEAR often included a multi-chamber arrangement that allowed the beam chamber to be isolated from a chamber that contained the distributed pumping elements in order to minimize beam impedance effects. (Beam chambers with a uniform cross section present the minimal impedance for transmission of high intensity particle beams. A large impedance can lead to heating of vessel components and induced wakefields that can affect beam trajectories [25]. The use of aluminum for storage ring vacuum chambers has generated a wealth of related development for the use of aluminum alloys in vacuum, such as effective surface cleaning methods [18] aluminum-stainless steel bonding methods [24, 26], vacuum certified aluminum welding and aluminum ultrahigh and extreme high vacuum components.[27]

As the synchrotron radiation power was increased in storage rings designed as dedicated light sources, specific synchrotron radiation absorbing structures had to be designed for the dipole magnet chambers to handle the localized heat loads. These structures have been as simple as copper bars brazed to the radiation plane of stainless steel chambers and as sophisticated as water-cooled absorbers with $\mathrm{Cu}, \mathrm{C}$ or $\mathrm{Be}$ as the radiation absorbing material.[28]

The development of two classes of distributed pumps for storage rings has had a significant impact on the further development of both ion pumps and non-evaporable getters. The innovative use in SPEAR of the dipole magnet fields as the confining field for ion pump Penning cells was an extension of the studies by Schurrman [29] and originally Penning [30] of the magnetic field dependence of cross-field gas discharges. Malev and Trachtenberg of Novosibirsk [31], and later Hartwig and Kouptsidis of DESY [32] developed specific formulas applicable to the design and performance of distributed ion pumps in both low and high field situations. 
For the $27 \mathrm{~km}$ Large Electron Positron (LEP) storage ring at CERN, a more cost effective distributed pumping scheme than the use of in situ ion pumps was required. LEP was the first to incorporate non-evaporable getter (NEG) pumps within the vacuum chamber as the primary pumping element. Impressive design analyses and prototype testing of the selected NEG system (SAES type 101, ZrAl alloy) were performed by CERN under the direction of C. Benvenuti [33]. As a result, the system has performed well for the entire lifetime of LEP (1989-2000).[19] (See Fig. 2). Numerous other storage rings $[34,35]$ had incorporated NEGs as the distributed pumping element even before the start-up of LEP. The most recent developments on the design and use of innovative distributed pumping involve the use of getter materials ( $\mathrm{Ti}, \mathrm{Vn}$ and $\mathrm{Nb}$ alloys) that are evaporated onto most of the surface area of the vacuum pipes leading to a cost effective, simple and high specific pumping speed solution to this engineering problem. [36, 37]

\section{Cold-bore accelerators}

What could very well be the last members of the family of colliders for high energy particle physics research are represented by the Superconducting Super Collider (SSC) in the U.S. (a project canceled in 1993), and the Large Hadron Collider (LHC) at CERN (which is under construction at CERN with projected completion in 2007). The enormous cost for these machines ( $>11 \mathrm{~B} \$$ for the SSC and $>4 \mathrm{~B} \$$ for the $\mathrm{LHC}$ ), which is the result of their size and need for thousands of state-of-the-art superconducting magnets, often outweighs discussions of the scientific benefits. The design work that has been accomplished for the SSC and LHC has already contributed to the UHV knowledge base because of the particular problems associated with storage ring vacuum chambers that must operate at liquid helium temperatures [38,39]. To minimize magnet costs the LHC beam chamber is relatively small in diameter $(\sim 5 \mathrm{~cm})$ and is thermally shunted to the magnet temperature ( $1.8 \mathrm{~K}$ for the LHC). 
Normally, the synchrotron radiation emission from the LHC proton beam would not be a problem in producing a dynamic gas load if the vacuum vessel was at ambient temperature. The photo-desorbed gases will not be readsorbed on nearby surfaces and would have a high probability of being removed from the gas phase by a modest array of distributed pumps. The case of photo-induced desorption and readsorption from surfaces near $4 \mathrm{~K}$ is quite different. All the desorbed species of interest $\left(\mathrm{CO}, \mathrm{CO}_{2}, \mathrm{CH}_{4}\right.$ and $\left.\mathrm{H}_{2} \mathrm{O}\right)$ except for $\mathrm{H}_{2}$ are pumped well and have low equilibrium vapor pressures on $4 \mathrm{~K}$ surfaces. Isotherm measurements on clean stainless steel at low temperatures show that $\mathrm{H}_{2}$ is pumped and the $\mathrm{H}_{2}$ vapor pressure remains low $\left(<10^{-11}\right.$ torr $)$ only if the $\mathrm{H}_{2}$ surface coverage remains below a monolayer [40, 41]. Dynamic pressures for the operation of LHC must remain below the $10^{-10}$ torr range in order to prevent excessive beam scattering and excessive heat load on the magnet cryostat as a result of the beam scattering. A design feature within the cold bore vacuum chambers to prevent the dynamic pressure from exceeding the $10^{-10}$ torr limit is the incorporation of an intermediate temperature liner (@ 20 K) between the beam aperture and the cold vessel wall. This liner would intercept the synchrotron radiation and be partially slotted or perforated to allow desorbed $\mathrm{H}_{2}$ molecules into the interspace. The $1.9 \mathrm{~K}$ operating temperature of the LHC cold bore is sufficiently low to pump $\mathrm{H}_{2}$ above monolayer quantities without exceeding the dynamic vacuum limits [42]. Related studies of photo-induced desorption phenomena at low temperatures (1.8-20 K) adds to our basic understanding of this important process and has application to other scientific and technical problems such as the formation of molecules on interstellar dust grain surfaces,[43] and the development of high capacity cryopumps.[44]

\section{Superconducting accelerators}


In addition to the use of superconducting magnets for saving power in accelerator operations, the other significant use of superconductivity in accelerator technology is RF acceleration cavities.[45] Linear accelerators are comprised primarily of an array of RF cavities, separated by occasional magnetic elements for correcting beam optics. In synchrotrons, the energy that the circulating beam loses due to synchrotron radiation and other processes is restored by RF cavities interspersed among the guiding magnets. For both applications, superconducting RF cavities save operating costs, offer lower impedance to the accelerating beam, and can be operated $\mathrm{CW}$ at high gradients. The disadvantages of superconducting RF cavities are the cost and complication of cryogenic cooling and the smaller operating experience. The latter concern has been alleviated with the operation of the CEBAF superconducting linac at Jefferson Lab in Newport News, Virginia [46] since 1993 and other large installations of operating superconducting RF systems at KEK [47], DESY [48], and LEP.[49] Presently, a 2MW superconducting linac system is under construction for the Spallation Neutron Source at ONRL [50]. Over 30 years of development has been invested in superconducting RF technology, resulting in the current state of the art which is capable of fabricating productionscale cavity assemblies with accelerating gradients greater than $25 \mathrm{MV} / \mathrm{m} .[51]$ These high performance cavities are also finding use in compact $\mathrm{CW}$ linacs for driving free electron lasers [52], which are being used for basic research and industrial applications such as materials processing where high average power and energy efficient UV and IR light sources are needed.[53] The successful development of superconducting RF cavities is strongly tied to UHV technology. High performance and reliable cavities require extremely careful cleaning and surface treatments, assembly in an environment free of particulate contamination, and vacuum sealing techniques which are UHV compatible.[54,55]

\section{E. Next generation accelerators}


The evolution of accelerators as shown on the "Livingston Plot" (Fig.1) was punctuated by new technologies that allowed performance to grow at affordable costs. Have the circular colliders reached this limit with the LHC? To provide alternative technologies for the next generation of particle accelerators, international collaborations are exploring designs options for the "Next Linear Collider" (NLC) project involving a pair of $250 \mathrm{GeV}$ linacs for $\mathrm{e}^{+} \mathrm{e}^{-}$collisions. Several teams are investigating warm accelerating structures from 3 to $30 \mathrm{GHz}$ [56], and a team at DESY has fabricated a prototype superconducting linac.[57] The primary problems with the warm structures, which are largely based on the success of the Stanford Linear Collider (which became operational in 1980 [58] shortly before LEP), are the extremely tight alignment specifications, and the observed erosion of prototype NLC vacuum chambers due to the intense, short pulse electric fields. The primary problem with the superconducting option is the projected cost of the superconducting cavity/cryostat structures. As in most endeavors competition is healthy, and the design and prototyping exercises have already generated valuable results in vacuum vessel materials, RF and cryogenic engineering.

\section{MAGNETIC FUSION DEVELOPMENT}

\section{A. The Roadmap}

The development of devices to harness thermonuclear fusion for power generation has an analogous road map to the "Livingston Plot" called the "Lawson Plot" based on John Lawson's calculations [59] of the minimum conditions of plasma density, plasma temperature and energy confinement necessary for energy break-even in a D-T plasma (see Fig. 3). For the first two decades of fusion research, devices were designed to magnetically confine and heat low-to-moderate density, hydrogenic plasmas. In such magnetic confinement schemes, plasmas

would have to obtain densities of $10^{19} \mathrm{~m}^{-3}$, temperatures of $10 \mathrm{keV}$ and energy confinement 
times $>1 \mathrm{~s}$ in order to reach the Lawson condition. This appeared to be a rather straight forward problem for the physicists and engineers who started this field of research over 50 years ago; however it has turned out to be one of the most difficult scientific and technical challenges of our times. A sustained effort over the last five decades from practitioners in Europe, Japan, Russia and the US has seen the plasma triple-product rise over ten orders of magnitude from the primitive, small devices of the 1950's to within $50-80 \%$ of the Lawson criterion using the gigantic tokamaks at Princeton [60] and Abingdon, England [61] in the 1990's. UHV technology has played a significant role in the development of magnetic fusion devices.

\section{B. First generation magnetic fusion studies}

The possibilities of fusion power or "controlled thermonuclear reactors" were clearly in the minds of physicists who witnessed the first man-made thermonuclear reactions with the explosion of the first D-T weapons. In the U.S. a secret program of fusion research was launched in the early 1950's code-named Project Sherwood.[62] This program had proponents who championed three different schemes for magnetically confining plasmas. Lyman Spitzer from Princeton University, who is generally given credit for having first elucidated the basic physics of magnetic confinement, conceived a figure-eight confinement geometry called a stellarator. A solenoidal field would confine the plasma, an inductively driven current would heat the plasma, and the twist in the field geometry would compensate for the tendency for charged particles to drift out of a simple toroidal geometry. James Tuck, a British physicist working at Los Alamos developed a scheme with his colleagues at Oxford to confine and heat plasmas by "pinching" the plasma to a small radius stream by rapidly increasing the toroidial field. A third team, led by Richard F. Post and Herbert York, at the Livermore branch of the 
University of California's Radiation Lab (the ancestor of Lawrence Livermore National Laboratory), proposed on open a solenoidal confinement scheme they termed "mirror machines". All of the early schemes were fraught with difficulties: the plasma confinement appeared poor, plasma temperatures were low, and the primitive vacuum technology that was used guaranteed that the plasma species of interest was overwhelmed by impurities from the confining chamber walls. When Spitzer had conceived the stellarator concept, he developed a plan for moving the technology along an orderly route from the pioneering Model A, which was a table top demonstration, to a larger Model $\mathrm{B}$, designed to push the plasma parameters, to an engineering prototype (Model C) which would be scale model reactor, to finally a full-scale prototype reactor (Model D).[63] This plan spells out many of the important subsystems that a fusion reactor would require: an auxiliary heating system to reach plasma ignition temperatures, a magnetic "diverter" to remove plasma impurities, and a lithium blanket for absorbing the fusion product neutrons and extracting energy from the reactor. The disappointing results coming in from the experiments on the B-series of stellarators, and similar results from the plasma pinch and mirrors programs, would considerably stretch out Spitzer's development plan for a reactor. Model $\mathrm{C}$ would not be a scale model reactor — it would be the next step in elucidating the plasma physics. When the Model C was commissioned in 1961, its stainless steel vacuum vessel became the largest UHV system built to date.[5] Special double joint, gold wire flange seals allowed the system to be baked to $450^{\circ} \mathrm{C}$. After bakeout, base pressures for the system were in the $10^{-10}$ torr range. Because of the concerns for hydrocarbon contamination, the Model $\mathrm{C}$ was pumped with two large mercury diffusion pumps that were isolated from the torus by lead-sealed valves and freon-cooled traps. Mercury was chosen as the pumping fluid because its accidental presence in the torus vacuum could be detected very sensitively by plasma spectroscopic techniques, and the high temperature vessel bakeout would easily remove the 
contamination. The performance of the Model $\mathrm{C}$ vacuum system was a huge success — the plasma performance on the other hand was disappointing. For most of the 1960's none of three confinement schemes being pursued in the U.S. or U.K. were making any significant forward progress toward the Lawson Criterion, and neither the measurements nor the theory could tell the experimenters why their plasmas remained relatively poorly confined and cold.[64]

The cold war prevented any significant exchange of information between the Western and Soviet programs except for brief interactions at plasma physics conferences organized by the International Atomic Energy Agency (IAEA). At the 1965 and 1969 [65] IAEA conferences, the Russians claimed that their toroidal magnetic chamber or "tokamak" geometry was producing plasmas with confinement times of milliseconds and plasma temperatures near a kilovolt. After confirmation of the Russian results by a visiting British team [66], the race to build tokamaks was on.

In the early 1970's tokamaks were under construction at Oak Ridge, [67] MIT [68], the General Atomics Co. [69] in San Diego, Princeton and in Europe. The confinement properties and stability limits of the tokamak geometry were confirmed and more importantly the energy confinement time appeared to improve with the square of plasma radius. Plans were quickly drawn up for a second generation of tokamaks by scaling up a factor of two in size, followed by another factor of two increase in size which would yield a device capable of reaching the Lawson condition. The Princeton Large Torus (PLT) [70] a tokamak with a 6,000 $\lambda$ vacuum vessel and $0.5 \mathrm{~m}$ plasma radius came on line late in 1975. With the use of high current, hydrogen neutral beams developed at Oak Ridge National Laboratory, PLT became the first fusion device to exceed the Lawson Criterion minimum temperature of $10 \mathrm{keV}$ in the summer of 1978. [71] Scientific and technical progress field came at an exhilarating pace for the next decade. 


\section{Plasma impurities and the vacuum vessel "first wall problem"}

The achievement of the high plasma temperatures in the PLT tokamak did not come without several key developments in controlling how the plasma interacts with the vacuum vessel wall. Spectroscopic and plasma resistivity measurements on the first generation of Western tokamaks were indicating that plasma impurities were a persistent problem. The ATC tokamak, at Princeton [72] achieved in 1974 the first pure hydrogenic plasma that was undiluted with carbon and plasma impurities desorbed from the vacuum vessel inner surface or "first wall". This result was achieved by evaporating titanium onto a large fraction of the vessel wall prior to a plasma discharge to suppress the impurities, combined with programmed injection of hydrogen during the discharge[73].

In 1975, the first in a series of compact, high field tokamaks built at MIT, Alcator A, also achieved pure, hydrogen plasmas [74] by a combination of UHV vessel design, programmed hydrogen gas injection, and the pioneering use of a pulse discharge cleaning technique to condition the vacuum vessel wall prior to exposure to high temperature plasmas. The discharge cleaning technique [75], developed by Robert Taylor, was rapidly adopted by all subsequent magnetic fusion experiments. Ironically, as a combination of the discharge cleaning and $\mathrm{Ti}$ gettering techniques was applied to the PLT device, low Z (carbon and oxygen) impurities were reduced to the point that these ions no longer cooled the edge plasma by radiation. The resulting edge plasma was sufficiently energetic to sputter excessive quantities of metal impurities from the tungsten "limiter" structure which defined the plasma radius and protected the vacuum vessel wall. A switch of limiter material to a high purity graphite solved the problem for PLT [76] and helped launch a development program for low $\mathrm{Z}$ refractory materials which would be needed for "first-wall" structures in the succeeding generation of tokamaks.[77] 
The problems of impurity generation and impurity suppression in tokamaks occupied significant portions of the experimental programs on many machines and led to several dedicated devices devoted to impurity studies.[78-81] Large scale tests of magnetic diverter structures for controlling the transport of both hydrogenic and impurities species were performed on the PDX tokamak at Princeton [82] and the ASDEX tokamak at Garching, Germany.[83] These two tokamaks, which became operational in the early 1980 's, required very large vacuum vessels $(\sim$ $36 \mathrm{~m}^{3}$ ) to contain the internal magnetic structures for the diverter and a ballast volume for pumping the plasma particles that were neutralized on the diverter target plate. The diverter volumes were equipped with large arrays of titanium evaporation sources to provide up to $2 \times$ $10^{5} \mathrm{l} / \mathrm{s}$ of hydrogenic pumping capacity. The PDX device was also used to test a prototype non-evaporable getter array [84] (based on the SAES Zr-Al alloy) and a large area, toroidal limiter for first wall protection fabricated from graphite tiles.[85] Because of the large size of the PDX and ASDEX vacuum vessels compared to the plasma volumes (6:1), both machines became test beds for developing hydrogen glow discharge techniques for cleaning complicated vacuum vessel structures $[86,87]$ that took advantage of the concurrent studies of glow discharge cleaning of accelerator structures.[17]

\section{Toward the energy breakeven demonstrations}

The rapid pace of the fusion program in the mid to late 1970's compressed and overlapped the design and operational schedules of three generations of machines. This accelerated schedule was most evident in the construction of the large tokamaks built to reach the Lawson criterion for energy breakeven demonstrations. Three large devices became the flagship experiments of the worldwide magnetic fusion program: the Tokamak Fusion Test Reactor [60] (TFTR) at Princeton began operating in 1982; the Joint European Torus, [61] at the 
Culham Laboratories in the U.K., began operating in 1982; and the JT-60 [88] tokamak at JAERI in Japan began operating in 1984. TFTR and JET were both designed to operate with D-T mixtures, and therefore had the complication of dealing with radioactive gas handling $[89,90]$ and the additional activation of the vessel [91] induced by the $14 \mathrm{MeV}$ D-T neutron fusion products. Initial operations in JT-60 were confined to hydrogen plasmas, and a subsequent upgrade of the machine (JT-60U) allowed the use of deuterium fueling.[92] D-T experiments in JET and TFTR began in 1992-93. Both machines achieved impressive plasma parameters on the Lawson plot (Fig. 3) [93] with the use of 20-30 MW of plasma heating [94-98] and frozen hydrogen pellet injection systems.[99] Plasma parameters within $80 \%$ of the minimum Lawson requirements were achieved in addition to pushing the plasma temperature records to 3-4 times the achievements of PLT.[97] Subsequent experiments at the upgraded tokamaks JT-60U [100] in Japan and the D III D [101] device (at General Atomics in San Diego) also achieved these high temperature regimes.

These performance of these large tokamaks required continued development of first-wall materials, first-wall structures, and conditioning techniques needed for edge-plasma particle and impurity control. The TFTR vacuum vessel was protected with a toroidal array of graphite tiles that is comprised of over 2000 tiles.[102] Special discharge cleaning techniques were developed to remove the large quantities of $\mathrm{H}_{2} \mathrm{O}$ absorbed by this structure during vents to atmosphere.[103] The highest performance discharges were achieved in TFTR after the graphite first-wall was induced to behave like a plasma pump by conditioning the structure with a regimen of special He discharges.[104] Prior to initiation of D-T discharges on TFTR, extensive studies of tritium trapping and removal mechanisms were developed to recycle tritium trapped in the vessel.[105] After operational experience was gained initially with the use of fine-grained graphite for first-wall armor, JET replaced graphite in high flux areas with Be [106], and the 
TFTR, DIIID and JT-60U devices upgraded to carbon-fiber-composite materials.[107] A pioneering application of a large scale vapor deposition process was demonstrated when the entire first-wall of the TEXTOR device in Germany was coated with thin layers of boroncarbide.[108] The technique was applied subsequently to many other tokamaks (ASDEX, TFTR, DIIID) as a means of in-situ modification of first-wall properties.

The careful control of the surface properties of the first-wall structures in large tokamaks would not be possible if high reliability "second-wall" or vacuum containment structures were not maintained. These complicated vacuum vessels must satisfy many constraints including: UHV standards for leak-tightness despite hundreds of access ports for diagnostic instrumentation and plasma heating equipment, structural integrity to withstand cyclic loading due to bakeout cycles, and large eddy-current-induced forces.[109] The need for high capacity, noncontaminating vacuum pumping systems for these large vessels drove the design of large (> $35001 / \mathrm{s}$ ) turbo pumps [110], and the associated high power neutral beam heating systems drove

the design of large He cryocondensation pumps with speeds exceeding $10^{6} 1 / \mathrm{s}$ for hydrogenic species.[111] As the magnetic fusion community continues with the engineering design of the next large fusion project, ITER, the "International Tokamak Engineering Reactor"[112], challenging vacuum technology problems will be encountered for design of effective first wall protection hardware, high capacity divertor pumping systems, and tritium delivery and recovery systems.[113-115]

\section{GRAVITY WAVE OBSERVATORIES}

After more than 25 years of development of high sensitivity laser interferometers, several large gravity wave observatories based on using this technique in large vacuum systems have recently come on line and are producing their first data. These observatories involve large diameter (1-1.2m) 
stainless vacuum vessels arranged in $\mathrm{km}$ length, perpendicularly intersecting sections to house the multi-path, laser interferometers in a Michelson configuration. The largest installation is the LIGO project in the US comprised of identical $4 \mathrm{~km}$ by $4 \mathrm{~km}$ interferometer legs at two stations near Livingston, LA and Hanford, WA.[116] Data from LIGO will be combined from similar data coming from the 2x3km VIRGO station near Pisa, Italy [117] the 2x600m GEO-600 station in Germany, [118] and the 2x300m TAMA station in Japan.[119] The vacuum requirements for these observatories are determined by the maximum tolerable light scattering due to fluctuations in the density of residual gases that would interfere with the detection of the extremely small motions $\left(<10^{-}\right.$ ${ }^{18} \mathrm{~m}$ ) of test masses located at the ends of the interferometer arms.[116]

These derived specifications put maximum partial pressure limits for $\mathrm{H}_{2}$ at $<10^{-8}$ torr and other residual gases such as $\mathrm{H}_{2} \mathrm{O}$ at $<10^{-9}$ torr; lower limits are put on hydrocarbons such as $\mathrm{CH}_{4}$ $\left(<10^{-14}\right.$ torr $)$ because of an additional concern for building up carbonaceous contamination on the surfaces of the sensitive optical elements. These partial pressure requirements and the large size of the vacuum vessels drove the need for developing a cost effective means of producing low outgassing rates in stainless steel in order to minimize pumping system costs. A relatively simple air bake procedure, demonstrated by a number of the gravity wave observatory teams, appears to satisfy these demands. Hydrogen outgassing rates below $5 \times 10^{-15}$ torr- $1 / \mathrm{cm}^{2}-\mathrm{s}$ and hydrocarbon outgassing rates below $10^{-16}$ torr- $1 / \mathrm{cm}^{2}$-s were obtained after a $400{ }^{\circ} \mathrm{C}$ bake of the stainless steel in air followed by an in-situ $150{ }^{\circ} \mathrm{C}$ vacuum bakeout.[117,118,120,121] The mechanism for reduction of the outgassing is still not determined, however thermal desorption measurements by Bradaschia et al at VIRGO $[117,121]$ indicate that the air bake is nearly as effective as an equivalent high temperature vacuum bake for the reduction of the low binding energy state of $\mathrm{H}_{2}$, which is presumably responsible for the primary share of hydrogen outgassing when the system is operated at room temperature. 
In addition to the requirement to minimize intrinsic outgassing of the vacuum vessel material, careful attention had to be paid to the design and implementation of the vessel welding for the multikilometer arms of the interferometer vessels, in order to insure that the gas load due to residual leaks and entrained gas in the welds was below the limits set for intrinsic outgassing.[120] With the use of the dual temperature bakeout procedure to lower the vessel material outgassing, and careful qualification and inspection of the extensive vessel welding, relatively modest vacuum pumping capability (provided by commercial sublimation and ion pumps) was sufficient to maintain the specified partial pressures for these large systems. Thus, the first generation of these impressive

machines has come on line meeting or exceeding their critical vacuum requirements while incorporating the largest ultrahigh vacuum vessels built for any purpose.

\section{ACKNOWLEDGMENTS}

This work was supported by U.S. DOE Contract No. DE-AC05-84ER40150.

This paper includes updates and condensations from a review paper given at 40th National Symposium of the American Vacuum Society that was published in J.Vac.Sci.Tech. A12, 862 (1994). (Reprinted with permission of the American Institute of Physics) and information from unpublished summaries from the AVS Workshop on XHV Science and Technology (Jefferson Lab, Newport News, VA, 2000) used with permission from the authors. The author thanks P.Redhead, K. Welch, M. Hablanian, R. Weiss and G. Krafft for useful comments on the manuscript. 


\section{References}

1. M. S. Livingston, "High-Energy Accelerators" (Interscience, NY, 1954).

2. G. K. O'Neill, Phys. Rev. 102, 590 (1956).

3. D. W. Kerst et al., Phys. Rev. 102, 590 (1956).

4. G. K. O'Neill and E. J. Woods, Phys. Rev. 115, 659 (1959).

5. G. Lewin and D. Mullaney, 1963 Vacuum Symp. Trans. (Pergamon, NY, 1964) p. 176.

6. C. Bernardini, G. F. Corazza, G. Ghigo and B. Touschek, Nuovo Cimento 18, 1293 (1960).

7. G. K. O’Neill, 1963 Super-High Energy Summer Study, No. 8 (Brookhaven National Laboratory, July 1993)

8. O. Gröbner, A. G. Mathewson, H. Störi and P. Strubin, Vacuum 33, 397 (1983).

9. SLAC Storage Ring Group, Proc. 8th Intern. Conf. on High Energy Accelerators CERN, 1971 (European Organization for Nuclear Research, Geneva, 1971) p. 145.

10. CERN Report No. AR/Int. SG/64-9 (1974).

11. R. S. Calder, Vacuum 24, 437 (1974).

12. A. Mathewson and M. H. Achard, Proc. 3rd Intern. Vacuum Congress, Vienna, 1977, R. Dobrozemsky et al., eds, (Berger, Vienna, 1977) Vol. 2, p. 1217; also see
A. Mathewson, Vuoto 17, 102 (1987).

13. E. Fischer, J. Vac. Sci. Technol. 2, 142 (1965).

14. E. Fischer, J. Vac. Sci. Technol. 9, 1203 (1972).

15. R. Calder and G. Lewin, Brit. J. Appl. Phys. 18, 1459 (1967).

16. A. G. Mathewson, in Proc. Intern. Symp. on Plasma Wall Interactions, Julich, 1976 (Pergammon, Oxford, 1977) p. 517. 
17. E. Fischer, Jpn. J. Appl. Phys. Suppl. 2, 199 (1974).

18. A. G. Mathewson, M. Andritschy, A. Grillot, O. Gröbner, P. Strubin in Surface . Conditioning of Vacuum Systems, AIP Conference Proc. No. 199 (AIP, NY, 1990) pp. $110-123$.

19. J. C. Billy, J. P. Bojon, O. Gröbner, N. Hilleret, M. Jimenez, P. Strubin, in Proc.European Particle Accelerator Conference, 2000.

20. J. LeDuff, Nucl. Instr. Meth. A239, 83 (1985).

21. H. J. Halama, in Vacuum Design of Synchrotron Light Sources, Y. G. Amer, S. D. Bader, A.R. Kraus, R.C. Niemann, eds, AIP Conference Proceedings No. 236 (AIP, NY, 1991) pp. 39-51.

22. T. Kobari, M. Matsumoto, T. Ikeguchi and S. Neda, in Ref. 21, pp. 347-354.

23. M. Andritschky, O. Gröbner, A. G. Mathewson, F. Schumann, P. Strubin and R. Souchet, Vacuum 38933 (1988).

24. U. Commings, N. Dean, F. Johnson, J. Jorow, J. Voss, J.Vac. Sci.Technol. 8, 348 (1971).

25. A. W. Chao and M. Tigner, Handbook of Accelerator Physics and Engineering, (World Scientific, NJ, 1999).

26. J. C. Schuchman, J. Godel, W. Jordan, and T. Oversluizen, J. Vac. Sci. Technol. 16, 720 (1979); also see J. C. Schuchman, J. Vac. Sci. Technol. A1, 196 (1983).

27. H. Ishimaru, J. Vac. Sci. Technol. A2, 1170 (1984).

28. Y. Morimoto, T. Shirakura, K. Konishi, S. Takahashi, S. Yokouchi and S. H. Bee, in Ref. 34, pp. 110-116.

29. W. Schurman, Physica 36, 137 (1967).

30. F. M. Penning and K. Nienhuis, Phillips Tech. Rev. 11, 116 (1949).

31. M. D. Malev and F. M. Trachtenberg, Vacuum 23, 403 (1973); 25, 211 (1975). 
32. H. Hartwig and J. Kouptsidis, J. Vac. Sci. Technol. 11, 1154 (1974).

33. C. Benvenuti, Nucl. Instr. Metho. 205, 391 (1983); C. Benvenuti and F. Francia, J. Vac. Sci. Technol. A8, 3864 (1990).

34. R. F. Niemann, R. Benaroya, M. Choi, R. J. Dortwest, G. A. Goeppner et al., Ref. 34, pp. 84-101.

35. S. H. Be, S. Yokouchi, T. Nishidono, Y. Morimoto, K. Watanabe et al., Ref. 3, pp. 102109.

36. C. Benvenuti, P. Chiggiato, P. Costa Pinto, A. Escudeiro Santana, T. Hedley, A. Mongelluzzo, V. Ruzinov, I. Wevers, Vacuum, 60,57 (2001)

37. C. Benvenuti, A. Escudeiro Santana, V. Ruzinov, Vacuum 60, 279 (2001)

38. W. C. Turner, J. Vac., Sci. Technol., A13, 2241 (1995)

39. A. G. Mathewson, in Proc. 1993 Particle Accelerator Conference (IEEE, Piscataway, NJ, 1993), pp. 3828-3832.

40. C. Benvenuti, R. S. Calder and G. Passardi, J. Vac. Sci. Technol. 13, 1172 (1976).

41. E. Wallén, J.Vac. Sci.Technol. A15, 265 (19970; A14, 2916 (1996)

42. O. Gröbner, Vacuum 46, 767 (1995); Vacuum 53,269(1999)

43. D. Hollenbach and E. E. Salpeter, J. Chem. Phys 53, 79 (1970); Astrophys. J., 163, 155 (1971).

44. M. G. Rao, P. Kneisel and J. Susta, Cryogenics, 34, 377 (1994

45. Y. Kojima, in Proc. 1991 Particle Accelerator Conference (IEEE, Piscataway, NJ, 1991) p. 16.

46. H. F. Dylla, L. R. Doolittle and J. F. Benesch, in Proc. 1993 Particle Accelerator Conference (IEEE, Piscataway, NJ 1993) p. 748. 
47. S. Mitsunoba et al., in Proc. of the 5th Workshop on RF Superconductivity, Hamburg, Germany, 1992, DESY Rep. No. DESY M-92-01 (April 1992), p. 84.

48. B. Aune et al., Phys.Rev.ST Accel. Beams 3, 092001 (2000)

49. G. Cavallari et al., LEP 2000 Status Report ,CERN-SL-98-011DI (March 1998)

50. Spallation Neutron Source (SNS) Project: www.sns.gov

51. A. Matheisen in Proc. of the $10^{\text {th }}$ Workshop on RF Superconductivity, Tskuba, Japan, 2001 www.conference.kek.jp/SRF2001/, paper TL007

52. G. R. Neil, S. Benson, G. Biallas, C. L. Bohn, D. Douglas et al., Phys.Rev.Lett. 84, 662 (2000).

53. M. Kelley, Proc.of the SPIE, 3888, 598 (2000).

54. J. Mammosser in Proc.of the 6th Workshop on RF Superconductivty, Newport News, VA 1993 (Jefferson Lab, Newport News, VA, 1994).

55. P. Kneisel, J.Vac.Sci.Tech. A11, 1575 (1993).

56. T. O. Raubenheimer, Proc.of the 2001 Particle Accelerator Conference (IEEE, Piscataway, NJ, 2001) p.407.

57. TESLA Technical Design Report, DESY Report 2001-001

58. M. Ross, in Ref. 45, p. 522.

59. J. D. Lawson, Proc. Phys. Soc. B70, 2 (1957).

60. R. J. Hawryluk et al in Proc. 11th Intern. Conf. on Plasma Physics and Controlled Nuclear Fusion Research, Kyoto November 1986 (IAEA, Vienna 1987) Paper No. IAEACN-47/A-I-3.

61. E. Bertolini, in Proc. 11th Symposium on Fusion Engineering (IEEE, Piscataway, NJ, 1986).

62. A. S. Bishop, Project Sherwood - The U. S Program in Controlled Fusion (Addison - 
Wesley, Reading, MA, 1958).

63. Lyman Spitzer et al., Problems of the Stellarator as a Useful Power Source (unpublished, June 1954).

64. J. L. Bromberg, Fusion: Science, Politics and the Invention of a New Energy Source (MIT Press, Cambridge, MA, 1982) pp. 130-150.

65. L. A. Artsimovich et al., Experiments in Tokamak Devices, Nuclear Fusion, Special Supplement 1969 (IAEA, Vienna, 1969).

66. N. J. Peacock, D. C. Robinson, N. M. J. Forest, P. D. Wilcock, and V. V. Sannikov, Nature, November 1, 1969, pp. 488-490.

67. G. G. Kelley, M. Roberts, and J. F. Clarke, Conceptual Design of the Ormak Facility, Oak Ridge National Laboratory Report ORNL-TM-2821 (unpublished, Dec. 3, 1969).

68. B. Coppie and J. Rem, Sci. Am. 227, 65 (1972).

69. R. L. Hirsch, Doublet II CTR Experiment at Gulf General Atomic (unpublished, Jan. 21, 1970).

70. H. P. Furth, Nucl. Fusion 15, 487 (1975).

71. H. Eubank et al., in Proc. 7th Intern. Conf. on Plasma Physics and Controlled Fusion Research, Innsbruch, 1978 (IAEA, Vienna, 1979) p. 11.

72. R. A. Ellis, H. P. Eubank, R. Goldston, R. R. Smith and T. Nagashima, Nucl. Fusion 6, 524 (1976).

73. P. E. Stott, C. C. Daughney, and R. A. Ellis, Nucl. Fusion 15, 431 (1975).

74. R. R. Parker, D. S. Pappas and E. Apgar, Bull. Am. Phys. Soc. 21, 1141 (1976).

75. L. Oren and R. J. Taylor, Nucl. Fusion 17, 1143 (1977).

76. E. B. Meservey, V. Arunasalam, C. Barnes, K. Bol, N. Bretz et al. J. Nucl. Mater. 93/94, $267(1980)$. 
77. W. B. Gauster, J. A. Koski, and R. D. Watson, J. Nucl. Mater. 122/123, 80 (1984).

78. R. A. Langley, R. J. Colchin, R.C. Colchin, R. C. Isler, M. Murakami, J. E. Simpkins et al., J. Nucl. Mater. 85/86, 215 (1979).

79. P. K. Mioduszewski, J. E. Simpkins, P. H. Edmonds, R. C. Isler, E. A. Lazarus et al., J. Nucl. Mater. 128/129, 884 (1984).

80. P. K. Mioduszewski, R. E. Clausing and L. Heatherly, J. Nucl. Mater. 85/86, 963 (1979).

81. M. A. Mahdavi, C. J. Armentrout, F. P. Blau, G. Bramson, N. H. Brooks et al., J. Nucl. Mater. 111/112, 355 (1982).

82. D. M. Meade et al., in Proc. Eight Intern. Conf. on Plasma Physic and Controlled Fusion Research (IAEA, Vienna, 1981) Vol. 1, p. 665.

83. M. Keilhacker et al., in Ref. 88, Vol. 2, p. 351.

84. J. L. Cecchi, R. J. Knize, H. F. Dylla, R. J. Fonck, D. K. Owens and J. J. Sredniawski, J. Nucl. Mater. 111/112, 305 (1982).

85. R. J. Fonck, M. Bell, K. Bol, K. Brau, R. Budny et al., J. Nucl. Mater. 111/112, 343 (1982).

86. H. F. Dylla, S. A. Cohen, S. M. Rossnagel, G. M. McCracken and Ph. Staib, J. Vac. Sci. Technol. 17, 286 (1980); H. F. Dylla, J. Vac. Sci. Technol. A6, 1276 (1988).

87. W. Poschenrieder, G. Standenmaier and Ph. Staib, J. Nucl. Mater 93/94, 322 (1980).

88. JT-60 Team, Plasma Phys. Contr. Fusion 28, 185 (1986).

89. P. H. LaMarche, H. F. Dylla, G. D. Martin, S. Raftopoulos in Proc. 13th Symposium on Fusion Engineering, Knoxville 1989, (IEEE, Piscatway, NJ, 1990) p. 96384.

90. The JET Team, J. Nucl. Mater. 196/198, 3 (1992)

91. E.E. Bloom, R. W. Conn, J. W. Davis, R. E. Gold, R. Little et al J. Nucl. Mater 122/123, $17(1984)$. 
92. H. Horiike et al., Fusion Eng. Des. 16, 285 (1991).

93. D. M. Meade, Fusion Eng., Proc. $17^{\text {th }}$ IEEE/NPSS Symposium, Vol. 2,752 (1997)

94. The JET Team, Nucl. Fusion 32, 187 (1992).

95. P. Andrew, C. J. Caldwell-Nichols, J. P. Coad, K. J. Dietz, J. Ehrenberg et, J. Nucl. Mater. 196/198, 143 (1992).

96. R. J. Hawryluk et al., Phys. Plasma 5,1577 (1998)

97. J. D. Strachan et al., Phys. Rev. Lett. 58, 1004 (1987).

98. M.Keilhacker et al., Nucl.Fusion 41,1925 (2001)

99. S. L. Milora, J. Vac. Sci. Technol. A7, 925 (1989).

100. K. Ushigusa and the JT-60 Team, Fusion Energy 1, 37 (1997).

101. E.A.Lazarus et al, Phys.Rev.Lett. 77,2714 (1966)

102. J. L. Cecchi, J. Nucl. Mater. 93/94, 28 (1980).

103. H. F. Dylla and the TFTR Team, J. Nucl. Mater. 145/147, 48 (1987).

104. H. F. Dylla et al.; Nucl. Fusion 27, 1221 (1987).

105. H. F. Dylla and K. L. Wilson, Eds, Tritium Retention in TFTR, PPPL Report No. 2523 and Sandia National Laboratories Report No. SAND-88-8212 (April 1988).

106. The JET Team, J. Nucl. Mater. 176/177, 3 (1990).

107. A. Miyahara and T. Tanake, J. Nucl. Mater. 155/157, 49 (1988).

108. J. Winter, J. Nucl. Mater. 176/177, 14 (1990).

109. W. G. Redan, J. Vac. Sci. Technol. 20, 1173 (1982).

110. R. Frank, E. Usselmann, Vakuum Technik 25, 48 (1976).

111. L. E. Valby, in Proc. of the 7th Symposium on the Engineering Problems of Fusion

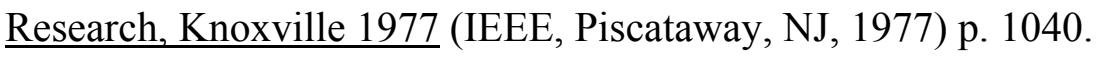

112. ITER Project: $\underline{w w w . i t e r . o r g}$ 
113. C. H. Skinner et al., J.Vac.Sci.Technol. A14,3267 (1996)

114. C. H. Skinner et al., J.Nucl. Mater. 290/293,486 (2001)

115. P. Andrew et al., Fusion Eng. Des. 47, 233 (1999)

116. A. Abramovici, W. E. Althouse, R. W. P. Drever,Y. Gursel, S. Kawamura, F. J. Raab et al., Science 256, 325 (1992)

117. V. Brisson, J. Hoang, G. Lissilour, P. Marin, A. Reboux, M. Bernardini, A. Pasqualetti, Vacuum 60, 9 (2001)

118. J. R. J. Bennett and R. J. Elsey, Vacuum 44, 647 (1993)

119. Y. Saito, G. Horikoshi, R. Takahashi and M. Fukushima, Vacuum 60, 3 (2001)

120. R. Weiss, Proc. XHV Workshop, June 2000, Jefferson Lab, Newport News, VA, (unpublished).

121. H. F. Dylla, Vacuum 47, 647 (1996) 


\section{Figure Captions}

FIG. 1. The "Livingston Curve" of the evolution of accelerator performance (1954), from Ref. 1 with an update by G. Krafft, Jefferson Lab (2003).

FIG. 2. Vacuum performance of LEP during its 10 years of operation, courtesy of $\mathrm{O}$. Gröbner, CERN, reprinted from Ref. 19 with permission.

FIG. 3. The "Lawson Criterion" for energy gain in D-T plasmas, courtesy D. M. Meade, Princeton Plasma Physics Laboratory, reprinted from Ref. 93 with permission. 


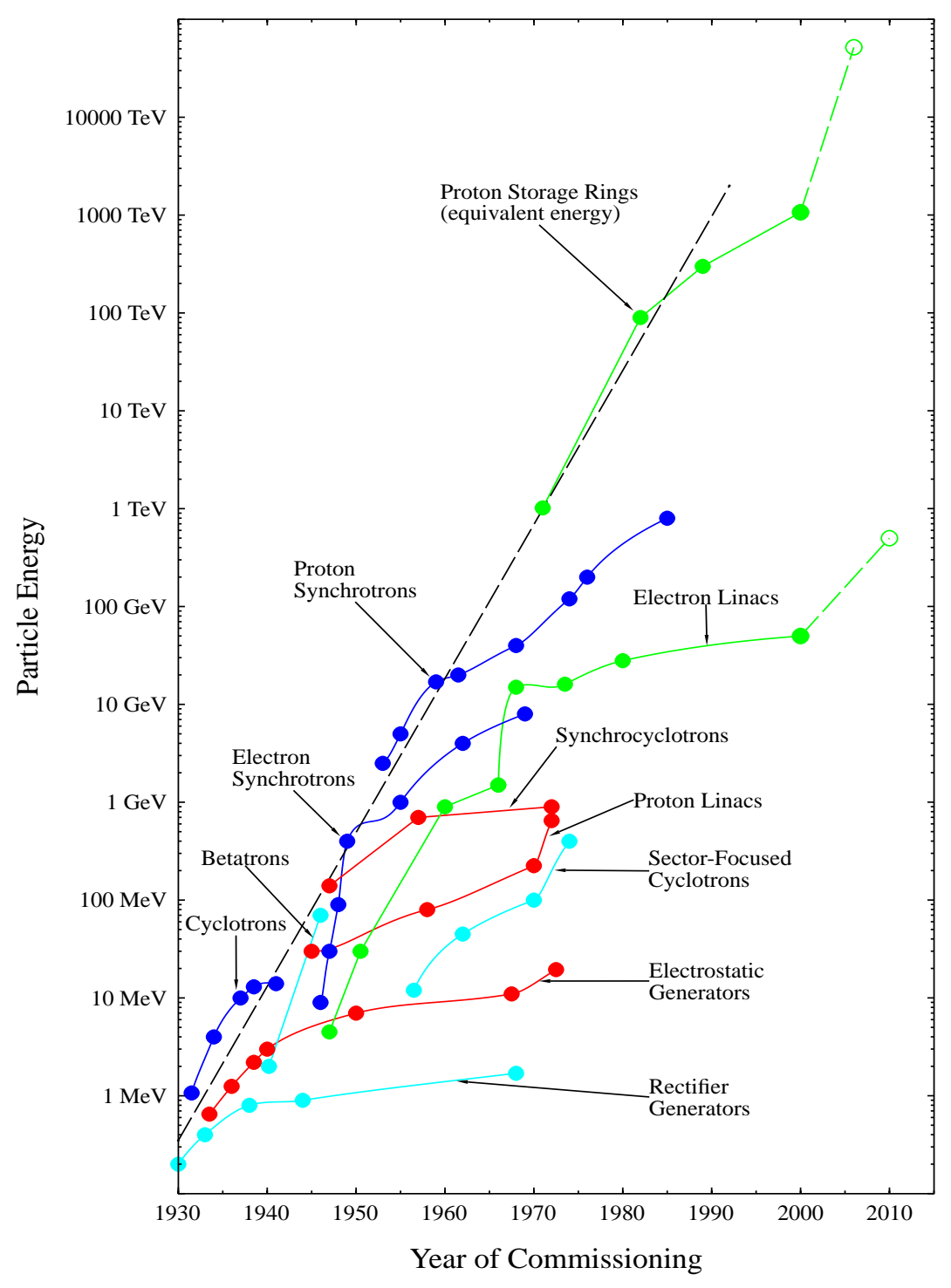




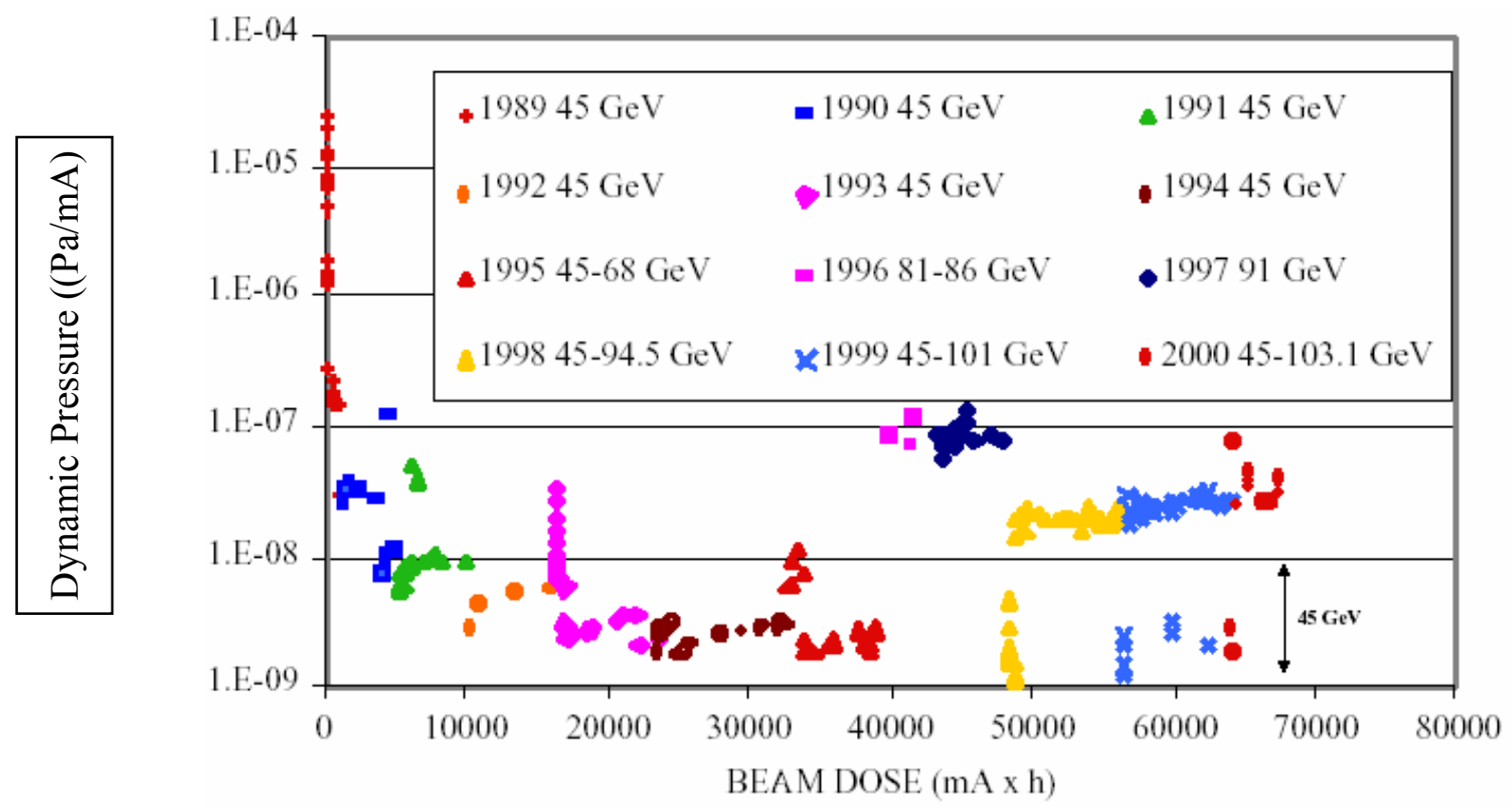

Figure2. The dynamic pressure evolution in CERN's Large Electron Proton (LEP) Collider over the 10 year operation of the device (Ref. 19) 


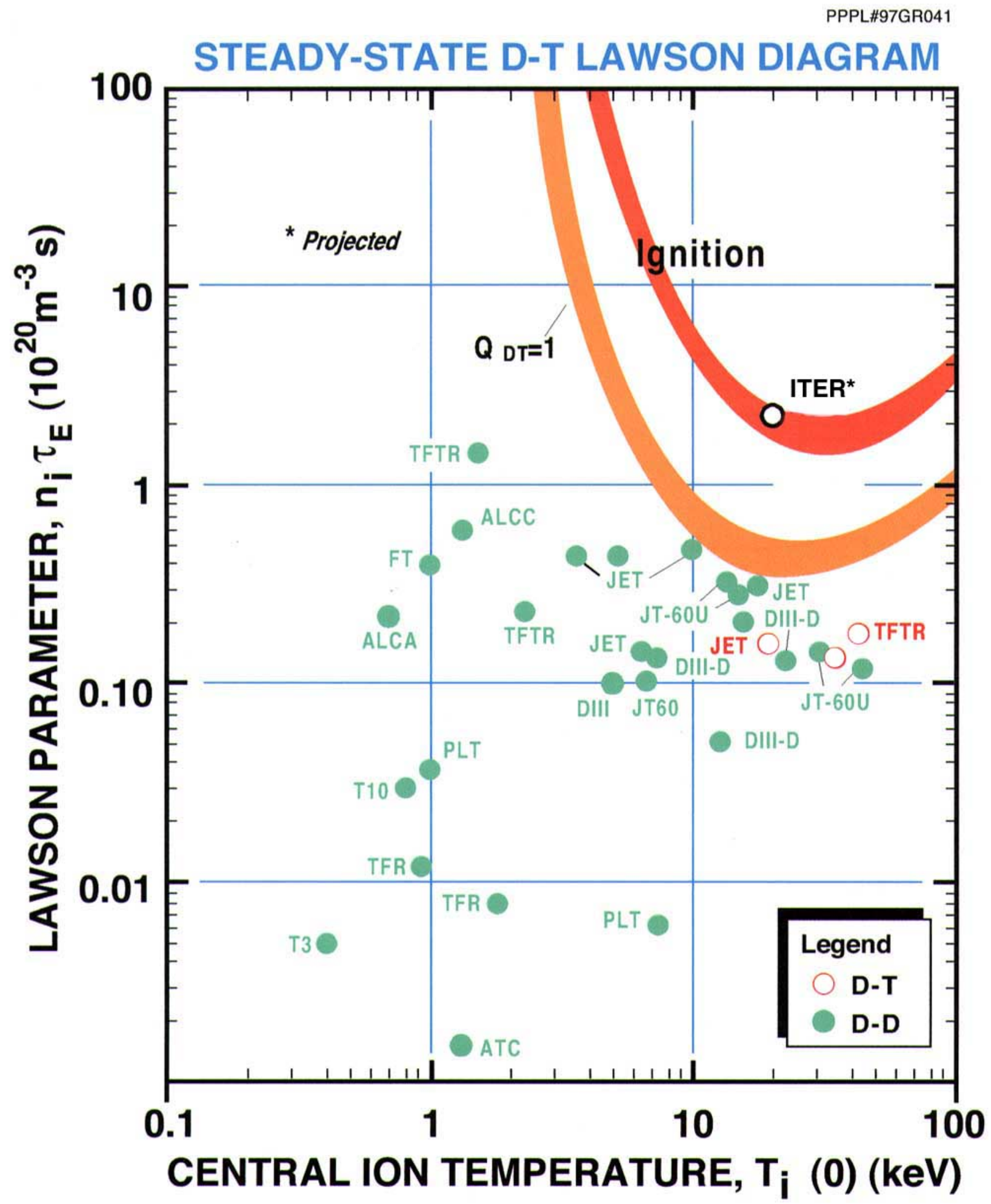

